\title{
1 Footprints and human evolution: homeostasis in foot function?
}

2

\author{
Matthew R. Bennett, Sally C. Reynolds, Sarita A. Morse, Marcin Budka \\ Institute for Studies in Landscape and Human Evolution, Faculty of Science and Technology, \\ Bournemouth University, Fern Barrow, Poole, BH12 5BB, UK.
}

\begin{abstract}
Human, and hominin tracks, occur infrequently within the geological record as rare acts of sedimentary preservation. They have the potential, however, to reveal important information about the locomotion of our ancestors, especially when the tracks pertain to different hominin species. The number of known track sites is small and in making inter-species comparisons, one has to work with small track populations that are often from different depositional settings, thereby complicating our interpretations of them. Here we review several key track sites of palaeoanthropological significance across one of the most important evolutionary transitions (Australopithecus to Homo) which involved the development of anatomy and physiology better-suited to endurance running and walking. The sites include the oldest known hominin track site at Laetoli (3.66 Ma; Tanzania) and those at Ileret (1.5 Ma; Kenya). Tracks from both sites are compared with modern tracks made by habitually unshod individuals using a whole-foot analysis. We conclude that, contrary to some authors, foot function has remained relatively unchanged, perhaps experiencing evolutionary homeostasis, for the last 3.66 Ma. These data suggest that the evolutionary development of modern biomechanical locomotion predates the earliest human tracks and also the transition from the genus Australopithecus to Homo.
\end{abstract}

Keywords: Ichnology, vertebrate tracks, human evolution, Laetoli, lleret

\subsection{Introduction}

Within the geological record, human footprints (tracks) occur infrequently as result of rare occurrences of sedimentary preservation (Aldhouse-Green et al., 1993; Roberts et al., 1996; Allen, 1997; Avanzini et al., 2008; Lockley et al., 2008; Kim et al., 2009; Schmincke et al., 2009 2010). Each set of tracks holds a potential glimpse into the locomotive behaviour of the track-maker. Currently the oldest and most famous hominin tracks are those at Laetoli in Tanzania made some $3.66 \mathrm{Ma}$ ago, preserved in volcanic ash and probably made by Australopithecus afarensis (Deino, 2011; Leakey and Hay, 1979; Leakey and Harris, 1987; White and Suwa, 1987; Bennett et al., 2016). In 2009, details of a track site close to the village of lleret in northern Kenya were published as the second oldest hominin footprint site, dating to $1.5 \mathrm{Ma}$ ago (Bennett et al., 2009). These footprints are believed to have been made by 
Homo erectus (Dingwall et al., 2013; Hatala et al., 2016a,b). Comparison of the lleret and Laetoli tracks has the potential, therefore, to explore the transition in locomotive style between Australopithecus, compared with the later genus Homo. This is one of the most significant evolutionary transitions from early habitual bipeds such as Australopithecus afarensis to endurance walkers and runners which characterise more modern humans such as Homo erectus and of course our own species (Bramble and Lieberman, 2004). The ability of our ancestors to walk efficiently would have influenced their interaction with the landscape, the way they foraged and hunted for food, gathered raw materials to use as tools, sought water, and their ability to migrate across the globe. The evolutionary pressure on the foot would have been intense, and therefore it is legitimate to ask if the evolution of the foot played a role in shaping human evolution as a whole across this transition, or alternatively was the course of evolution, with respect to foot function, set much earlier?

Tracks have the advantage over fossil foot bones because not only are such bones rare in the fossil record (e.g., Clarke and Tobias, 1995; Gebo and Schwartz, 2006; Ward et al., 2011; Zipfel et al., 2011; Granger et al. 2015; Harcourt-Smith et al., 2015;), but in truth, fossil foot bones alone rarely give an unambiguous indication of the way our early ancestors walked, since the 26 bones of the foot act through a series of complicated soft tissues which are not preserved. Our aim is to explore here the potential of tracks to assess the evolution, or lack of it, across the australopith to Homo transition.

\subsection{Methods}

The quantitative study of vertebrate tracks, including hominin tracks, is being transformed by the increasing availability of techniques to digitally capture tracks in three-dimensions whether by optical laser scanning or by digital photogrammetry (Bennett et al., 2013). All the data used here was captured using a Konica-Minolta (Vi900) optical laser scanner housed in a custom built rig to support the scanner horizontally and shield it from dust and excess sunlight (Bennett and Morse, 2014). The data was acquired either as a consequence of direct excavation, or in the case of Laetoli, by scanning first generation casts of the tracks held at the National Museums of Kenya (Nairobi). The data for the lleret track site is based on that available to the authors at the end of 2010.

Digital data were exported as xyz point clouds and processed within freeware written by the authors (DigTrace, available from: www.DigTrace.co.uk). This integrated software package allows for the creation of three-dimensional models via photogrammetry, their analysis and comparison using a whole foot technique. The creation of a mean track for a population of tracks, or trackway, and the comparison of two or more tracks (or means) is achieved by a whole-foot registration technique (Bennett et al., 2016).

The registration process requires the user to denote one track in a series as a "master" with which all the remaining prints are aligned by defining corresponding landmarks (matching points) on each track. Selection of the master is guided by identifying which track is most anatomically complete. Landmarks are placed on the basis either formally defined anatomical points or informally defined 
points of recurrence (i.e. point matching). These landmarks can also be complemented by "geometrical" landmarks, located for example between defined landmarks. DigTrace currently supports three types of geometrical landmarks: line, triangle and square, where an artificial landmark is inserted in the centre of gravity of each pair, triplet or quadruplet of the user-defined landmarks, respectively.

DigTrace then computes a transformation of the source print to align it with the master, by minimising the mean squared deviation between the landmark coordinates. Denoting by $Y$ a matrix of landmark coordinates for the master print (one landmark per row) and by $X$ a matrix of corresponding landmark coordinates of the print to be registered, the software calculates the transformation matrix $W$ as an approximate, optimal in the least square sense, solution to the following system of equations:

$$
Y=X W
$$

DigTrace supports two types of transformation. Firstly, affine transformation, where the matrix $W$ is not constrained in any way and is calculated as:

$$
W=\left(X^{T} X\right)^{-1} X^{T} Y
$$

where the matrix $X$ is supplemented by a column of 1's to account for the intercept term, hence allowing for translation. Secondly, rigid transformation, where the matrix $W$ is constrained to represent a valid rotation only. Denoting by $A=X_{c}^{T} Y_{c}$ the covariance matrix of $X$ and $Y$ after centering (i.e. subtracting their respective centroids, which accounts for translation), the optimal transformation can be calculated as:

$$
W=\left(A^{T} A\right)^{1 / 2} A^{-1}
$$

For numerical stability this operationalised in the software using the Kabsch algorithm (Kabsch, 1976) which calculates $W$ via singular value decomposition of the covariance matrix. Once tracks are aligned all the registered tracks are sampled using a grid to create mean depth and other measures of central tendency for all the points on that grid.

\subsection{Austropithecus-Homo transition: localities and tracks}

\subsection{Laetoli - Australopithecus}

The most iconic of all hominin track sites is at Laetoli in northern Tanzania (S 3 $3^{\circ} 13^{\prime} 29.6911 "$ ", E $35^{\circ}$ 11 '30.3158). This series of trackways was first discovered and excavated in the late 1970s and are now dated to $3.66 \mathrm{Ma}$ (Deino, 2011; Fig. 1). The site provides one of the earliest direct sources of evidence for hominin bipedalism (Leakey and, Hay 1979; Leakey, 1981; Leakey and Harris, 1987; Meldrum et al., 2011). 
The site lies $36 \mathrm{~km}$ south of Olduvai Gorge and a total of 18 track sites have been found, of which approximately half have been recorded (Musiba et al., 2008). The Laetoli Beds overlie Precambrian basement and can be divided into a lower unit (64 m thick) that consists mainly of air-fall tuffs and water-worked tuffaceous sediments, and an upper unit (44-59 m thick) of air-fall tuffs (Drake and Curtis, 1987; Hay, 1987; Ditchfield and Harrison, 2011). The famous Footprint Tuff bearing the hominin tracks (Leakey and Hay, 1979; Leakey and Harris, 1987) is found in the upper unit. Hay (1987) interpreted the footprint tuffs as having an aeolian origin and suggested that the tephra was deposited over a period of a few weeks at the transition between the dry and wet seasons. According to Lockley et al. (2008), over 9,500 individual animal tracks have been recorded, of which the vast majority are rabbits or hares. Other animal tracks include examples of monkeys, antelopes, elephants, rhinos, three-toed horses, cats, hyenas, giraffes, guinea fowl and francolins (Leakey and Harris, 1987; Musiba et al., 2008). The main hominin site (Site-G) is approximately $27 \mathrm{~m}$ long and consists of three trackways, two of which (G-2 and G-3) are superimposed with a second track-maker (G-3) walking crudely in the footsteps of the first (G-2). Due to the superimposed nature of the G-2 and G-3 trackways attention has largely focused on the G-1 trackway generating extensive debate and analysis within an ever-growing literature (e.g. Meldrum et al., 2011). The track-maker has been widely attributed to Australopithecus afarensis given that a small number of skeletal fragments have been recovered from the Laetoli Beds and it is also the only species of hominin known from the region during this time period (Suwa, 1984; Leakey and Harris, 1987; White and Suwa, 1987). This view is not shared by all however, with some pointing to the possibility of a hitherto un-recorded hominin species as being the potential track maker (Tuttle et al., 1990). White and Suwa (1987) suggest that the track-maker for trail G-1 had a height in the range of 1.1 to $1.15 \mathrm{~m}$ while the G-3 track-maker was slightly taller at $1.32-1.52 \mathrm{~m}$. Tuttle et al. (1990) revised these estimates to 1.22 and $1.44 \mathrm{~m}$ respectively based on their modern analogue data. Figure 2 shows a mean track computed using eleven usable prints from the G1 trackway and a mean for the G3 trackway extracted from the G2-G3 composite (Bennett et al., 2016).

\subsection{Turkana Basin- $\underline{\text { Homo }}$}

The Koobi Fora Formation, Turkana Basin (northern Kenya; N 3 56' 52.9224", E 36 $\left.11^{\prime} 12.0264^{\prime \prime}\right)$ contains two track sites. The older at $\sim 1.52$ Ma was reported in 2009 at a site close to the village of Ileret within the Okote Member of the Koobi Fora Formation (FwJj14E; Bennett et al., 2009). The second site was first described by Behrensmeyer and Laporte (1981) and lies $40 \mathrm{~km}$ to the south. FWJj14E consists of an eroding bluff of sediment capped unconformably by Holocene sediments (Galana Boi Formation; Feibel et al., 1989). Excavation at various levels has found multiple track surfaces and is on-going. The surfaces described here are those of 2009 excavations and are located at two stratigraphic levels, with isolated hominin and animal track-bearing strata between (Figs 3 and 4; cf. Hatala et al., 2016b). The sedimentary succession consists of over $9 \mathrm{~m}$ of finegrained, normally graded, silt and sand units $(0.1$ to $0.5 \mathrm{~m})$ between thicker $(0.5$ to $2.0 \mathrm{~m})$ palaeosol units with at least three tuffs used for dating. Isaac and Behrensmeyer (1997) suggest that the 
sediments around Ileret form part of a low energy fan-delta with numerous seasonally dry distributaries draining into a lake which may have gradually transgressed over at least part of this area. There is no evidence of this transgression at FwJj14E and track-bearing horizons consist of fining-upward waning sheet flood deposits, in which course sand drapes underlying deposits (and/or the previous flood cycle) fining upwards to fine silts, which appear to have been emergent but are not unduly desiccated. They may be representative of either crevasse splays, or simply over-bank floods on a low lying flood- or delta-plain. There has been some revision since Bennett et al. (2009) with respect to the sequence of tracks (Dingwall et al. 2013; Hatala et al., 2016b). The upper track horizon, and the best, consists of a number of isolated prints and one short trail of nine prints which is interpreted by Dingwall et al. (2013) as being made by two individuals travelling in a similar direction (Fig. 3). All the human tracks occur in association with a rich record of mammals and birds. Walking speeds of between 0.45 and 2.2 ms-1 made by heavy ( 41.5 to $60.3 \mathrm{~kg}$ ), tall individuals (1.526-1.858 $\mathrm{m}$ ) are proposed for this track (Dingwall et al. 2013). The prints were tentatively attributed by Bennett et al (2009) to Homo erectus, although Dingwall et al. (2013) has suggested that they could have been made by a male Paranthropus boisei (see also: Hatala et al., 2016b; Roach et al., 2016). Using all the available tracks on both the upper and lower surface a mean was created (Fig. 5A). It is important to note that many of the tracks show taphonomic influence particularly associated with side wall suction on foot withdrawal which gives rise to long, narrow tracks with little plantar detail. The impact of other animal tracks both prior to and after imprinting is clear in most prints (Fig. 4A) and also adds to the noise associated with this mean. Additional tracks from this site have been excavated more recently are reported by Hatala et al. (2016b) and are ascribed to predominantly male trackmakers probably of Homo erectus, potentially moving as hunting groups (Roach et al., 2016).

Approximately $45 \mathrm{~km}$ to the south of lleret, there is a second footprint site (GaJi10), first reported by Behrensmeyer and Laporte in 1981 consisting of a single trackway of poorly defined prints which is in contrast to those at lleret, and may have been imprinted subaqueously or at least in shallow water (Bennett et al., 2014a). The footprint surface occurs below a prominent tuff, sampled and correlated to the Akait Tuff dated to $1.435 \mathrm{Ma}$ (Brown et al., 2006; Bennett et al., 2009). Re-excavation of these prints by Bennett et al. (2009) uncovered four of the original seven prints. The lithofacies around GaJi10 is consistent with a low energy fluvial-lacustrine system subject to both short-term seasonal and millennial-scale water variations (Behrensmeyer, 1975; Lepre et al., 2007). This landscape was rich in a diverse range of vertebrate and semi-aquatic fauna and has yielded a plethora of vertebrate remains with aquatic and semi-aquatic fauna being more common around GaJi10 (Behrensmeyer, 1975; Bennett et al., 2014a).

The original surface excavated by Behrensmeyer and Laporte (1981) contains over 89 distinct impressions (c. $12 \mathrm{~m}^{2}$ ) identified as the tracks of large vertebrates (hippopotami) in addition to the short hominin trackway. According to Behrensmeyer and Laporte (1981) the site was covered by shallow water an interpretation based in part on the presence of a wading bird track, although it is possible that the hominin trackway was made at a subsequent lake low-stand. Behrensmeyer and Laporte (1981) attributed the tracks to Homo erectus, an interpretation supported by Bennett et al. 

the sub-aqueous conditions. A second excavation on the same palaeo-surface has been excavated 80 metres to the south and contains over 240 individual tracks interpreted by as being formed by swimming hippopotami 'punting' or bottom-walking along the bed of a shallow water body (Bennett et al., 2014a). The depth of this water body is estimated at between 0.5 and $1.5 \mathrm{~m}$ and is a deeper water equivalent to that found in the excavation further north in which the hippopotami tracks were formed by normal walking (the water body being too shallow to allow swimming). This animal assemblage provides a sharp contrast to that described at lleret which is subaerial and dominated by bovid, suid and equid tracks.

In order to provide a modern control, data was collected for 33 habitually unshod Daasanach at lleret in 2008. The individuals were asked to walk at a comfortable pace across a pre-prepared experimental plot held at constant moisture content and filled with sand and silt from the backfill pile at FWJj14E. The chosen moisture content was based on maximising the sediment cohesion and was maintained using a simple moisture probe. The single right track was selected from the dozen or so left by each individual and scanned. A mean track was then created in DigTrace (Fig. 5B).

201

\subsection{The Australopithecus-Homo transition: track comparisons}

Figure 6 shows unregistered and registered means for the track populations in this study. The upper part of this figure shows the tracks at their relative sizes, while in the lower half of the figure the influence of size has been removed. Figure 7 shows the standard deviations for the various track means when registered in different combinations against each other using DigTrace. Positive and negative areas of difference are highlighted by the 1 standard deviation contours, with red (+ve) and blue (-ve) areas showing areas of maximum divergence between the registered mean tracks.

The lleret tracks have a narrow, tapering heel consistent with a softer substrate in which foot withdrawal causes side-wall suction and a decrease in width. The enhanced longitudinal asymmetry (deeper ball than heel) is also a feature of softer substrate (Morse et al., 2013). The substrate first holds the weight of the individual during the first phase of stance, only to fail further during the second phase associated with higher plantar pressures during toe-off. The lack of clarity of toe impressions is also a feature of deeper prints where foot withdrawal often modifies the impressions left by phalanges. The medial longitudinal arch is also modified in softer substrates by the proximal movement of sediment under rotation of the ball of the foot. The lleret mean track is derived from a highly variable and deep set of tracks which show taphonomic influences and the influence of a relatively weak, fine-grained substrate with a high level of stratigraphic turbation due to animal trampling and elevated pore-water content. For all these reasons, and the overall greater track depth, 
the relationship between biomechanical pressure and depth is likely to be poor (Bates et al., 2013a). It is worth noting, however, that individual track fragments not included in the mean, particularly of the forefoot, provide good anatomical impressions, suggesting that the toes were similar in morphology and length to those of modern humans (Bennett et al., 2009; Fig. 4C). It is our view that given the data available, the mean does not remove the influence of substrate to reveal a viable track for biomechanical comparison. These tracks remain important due to their association with other animals and because they may say something about the activity, for example hunting, of the track-makers but unless better, shallower tracks from more uniform substrate areas in terms of sedimentology then biomechanical inferences should only be made, if at all, with extreme caution. Note also that the tracks from Koobi Fora described by Behrensmeyer and Laporte (1981) are not included here because there is insufficient anatomical detail to allow comparison. The fact that these tracks may have been formed subaqueously is probably the reason for the lack of preserved detail.

There is a greater topological similarity between the G1/G3 and the modern Daasanach means (Figs 9 and 10). Both sets of tracks were made in drier substrates with more spatially, along the trackway, consistent sedimentological properties. Both sets of tracks are shallower and therefore more ideal for making biomechanical inferences (Bates et al., 2013a).

Comparing the G3 mean to the Daasanach mean the differences are restricted to a slightly variation in depth along the lateral side of the modern foot. The modern foot is more impressed and may reflect a subtle difference in the degree to which the longitudinal medial arch is developed in the case of the G3 mean. It should be noted however, that this arch becomes slightly less pronounced as substrates become firmer and the difference may therefore also reflect greater compaction of the G3 track in the base of the $\mathrm{G} 2$ track. The $\mathrm{G} 1$ mean has a slightly less developed arch when compared to the Daasanach mean (Fig. 7), although in the case the key difference is the shape and depth of the heel area; it is deeper and more elongated in the case of the G1 mean. There is a lack of clear anatomical difference between the Laetoli and modern tracks therefore supporting the conclusion of Crompton et al. (2011) that both sets of tracks are biomechanically similar in form.

Hatala et al. $(2016 a, c)$ stress the importance of medial transfer as the defining characteristic of modern foot function. The implication is that this is less well developed in the Laetoli tracks (Hatala et al. $(2016 a, c)$. This is consistent with the landmark based analysis of the lleret tracks (Bennett et al., 2009) who suggested that they showed a greater mechanical affinity to modern Homo sapiens prints rather than to Laetoli. Figure 8 shows data on the deepest point in the ball area of tracks for both Laetoli and a sample of modern tracks in excess of 695 individuals. What is clear from this is that modern feet show a range of behaviours and the degree of medial transfer is variable within a large population. This is consistent with Bates et al. (2013b) who suggested that in a small group of modern humans the foot showed greater mid-foot flexibility giving rise to an effective mid-tarsal break and a lack of medial transfer in some tracks. Not only does this data challenge the idea that medial transfer is a defining characteristic of modern gait (cf. Hatala et al. 2016a; Fig. 8), but the Laetoli tracks while showing less medial transfer, evident in the G1 and G3 means (Fig. 2), are not atypical of the variability in modern foot function. The difference between the Laetoli tracks and those of modern 
humans are small, and what variances are visible appear to focus on the degree to which the medial longitudinal arch is developed, which itself appears potentially to be enhanced primarily within the genus Homo.

Recent work by Hatala et al. (2016c) has added to this ongoing debate. They use 14 functionally important locations across tracks to compare modern human $(n=245)$ and chimpanzee tracks $(n=24)$ with those of Laetoli $(n=5)$. The different track samples were not co-registered, unlike this study and that of Crompton et al. (2011), and the 14 points apparently placed by 'eye'. They used Mahalanobis distances to model and compare the means of different samples, of varying sizes. The computed distances show statistical differences suggesting a distinction in track morphology between the three sampled populations. Hatala et al. (2016c) interpret this in terms of the Laetoli track maker ( $A$. afarensis) having a more flexed lower limb posture than is typical for modern humans. This may not be as extreme as the bent knee and/or hip flexion hypnotised and debated by some (Raichen et al. 2010; Crompton et al., 2011). Hatala et al. (2016c) draw attention to the presence of only a moderate medial weight transfer in the Laetoli tracks as further evidence of their interpretation of a more flexed biomechanical motion.

\subsection{Conclusion}

The lack of difference in track topology, and therefore by inference biomechanical function, between Australopithecus tracks and ones made by modern Homo sapiens identified in this paper may suggest that foot functional anatomy over the last $3.66 \mathrm{Ma}$ has remained relatively unchanged. This supports the conclusions of Crompton et al. (2011), but challenges those of Hatala et al. (2016c). This does not necessarily mean that the track-maker at lleret, assumed to be Homo erectus (Bennett et al., 2009; Dingwall et al., 2013), had a similarly modern foot function since these tracks are in the author's opinion dominated by the influence of substrate. Hatala et al. (2016a) point to the medial shift in the later part of stance as the defining element of modern gait, a feature that is present in the lleret tracks (Hatala et al., 2016b). Figure 8 however shows that modern human foot function has a range of variability with respect to the degree of medial transfer. This variability encompasses that present in all of the populations sampled here, including those at Laetoli. We do not necessarily therefore agree with the conclusions of Hatala et al. (2016c) that there is sufficient distinction in the degree of medial transfer to allow locomotory discrimination between the Laetoli track-maker and modern humans.

To this we must add a word of caution implicit in this type of analysis and remember that we are in practice making critical inferences about whole genera from a very limited sample of tracks! The more we sample modern human foot function the more variable it appears to become (Fig. 8; Bates et al., 2013b). In addition some researchers have suggested that the Laetoli track-makers may have had specific pathologies or been undertaking specific behaviours leading to non-standard tracks (e.g., Tuttle et al., 1990). Ultimately we have the data that we have and while further data is always 
desirable and might be forthcoming from Laetoli in time with new discoveries, we need to take a view, at least in the interim, with what we have. Therefore as things stand we tentatively suggest, as stated above, that the biomechanical differences present within the tracks sampled here are within the range of variability of modern humans and are therefore left with the most parsimonious conclusion that primary foot function (i.e. walking) has varied little during the last 3.66 Ma.

The evidence from fossil bones provides a slightly different picture, suggesting that different genera/species may have slightly different locomotor repertoires (e.g., Gebo and Schwartz, 2006; Harcourt-Smith et al., 2015). A combination of anatomical features suggests that both terrestrial bipedality and arborealism is evident as far back as Oreopithecus (Szalay and Langdon, 1986; MoyàSolà et al. 1999). Lovejoy et al. (2009) suggest that the robust nature of metatarsals two and three in Ardipithecus ramidus indicates a role in applying accelerative force in the later part of bipedal stance, while an abducted hallux might have provided grip on branches, and therefore conclude that locomotion involved both arboreal climbing and terrestrial bipedalism. Australopithecus sediba has been reported by Zipfel et al. (2011) to possess ankle and foot morphology that would facilitate a range of both arboreal and terrestrial bipedal locomotion and evidence for a strong Achilles tendon may suggest adaptation for energy efficient terrestrial running. Furthermore the mid-foot of $\mathrm{OH}-8$, traditionally ascribed to Homo habilis is variously described as having an 'apelike' talus combined with strong longitudinal arches (Day and Napier, 1964), or an un-stabilised medial mid-foot with no medial arch, combined with a stabilized calcaneocuboid joint on the lateral side (Kidd et al., 1996).

The retention of both arboreal and terrestrial bipedal attributes within the foot can be interpreted in different ways. For example, Harcourt-Smith and Aiello (2004) suggest that this range of functional morphology indicates multiple paths to bipedalism (mosaic evolution) in early hominins as evidenced by the anatomical mosaicism present. The alternative is to suggest that this range of functionality might instead simply be due to a high degree of functional redundancy in the 26 bones and associated $80+$ ligaments present. Evidence presented by Bates et al. (2013b) suggests that retained mid-foot mobility occurs in modern humans and amounts effectively to a mid-tarsal break in some but not all steps and that there is greater overlap in foot function between hominins and great apes than is often implied (see also: Wolf et al., 2004; Crompton et al., 2010, 2012).

One reason for the retention of this functional flexibility (or redundancy) is that unshod humans rarely walk on flat and stable surfaces, but instead on uneven ground where foot flexibility is critical to balanced, safe and cost-effective locomotion. Most fossil tracks (and associated laboratory studies) do not account for this, since they involve walking on relatively flat surfaces, although potentially muddy and slippery ones. It is therefore perhaps not surprising to find a convergence in foot behaviour across different genera walking on flat terrain, especially since subtle skeletal differences in the 26 bones can be compensated for by the $80+$ ligaments in the foot. In the context of other terrain types and foot functions the retained redundancy is not redundant at all. One could go as far as to suggest that functional flexibility/redundancy in the foot is perhaps a defining and important evolutionary characteristics conferring an advantage that allows for a wide range of possible motions 
from climbing to endurance walking and/or running. This flexibility is something that we perhaps now underestimate as habitually shod individuals.

This speaks to recent debates about the origins of hominin bipedalism and the importance of complex topography (Winder et al., 2013, 2014) which challenges the more conventional arboreal hypotheses (Thorpe et al., 2007, 2014a, b; Crompton et al., 2010). This remains contentious, with potentially no simple, or single explanation (Wood, 2014; Allen et al., 2015), however retention of functional flexibility/redundancy would allow hominins to use both arboreal and rocky refuges while evading predators, as well as cope with rough and variable terrain and different types of ground surfaces. These behavioural drivers may have in reality changed little over the last 3.66 Ma.

\section{Acknowledgements}

This work was funded by NERC grants (NE/H004246/1 and NE/M021459/1) and Bournemouth University. Bennett would like to thank Jack Harris, Brian Richmond, Melanie Crisfield and the staff and students of the Koobi Fora Field School. The National Museums of Kenya is acknowledged with thanks for providing access to the first generation cast of the Laetoli tracks in 2008. Bennett and Morse would like to thank Robin Crompton and Todd Pataky for useful discussion about whole foot methods. The assistance of Samantha Underhill, Rashid Bakirov and Shujie Deng is gratefully acknowledged. DigTrace can be obtained from www.digtrace.co.uk.

\section{References}

Aldhouse-Green, S.H.R., Whittle, A.W.R., Allen, J.R.L., Caseldine, A.E., Culver, S.J., Day, M.H., Lundquist, J., Upton, D., 1993. Prehistoric human footprints from the Severn Estuary at Uskmouth and Magor Pill, Gwent, Wales. Archaeologia Cambrensis 141, 14-55.

Allen, A., Crompton, R.H., Winder, I.C., D' Août, K., 2015. Walking over complex terrain: a systematic review. Footwear Science 7(S1), S29-S30, DOI:10.1080/19424280.2015.103830

Allen, J.R., 1997. Subfossil mammalian tracks (Flandrian) in the Severn Estuary, SW Britain: mechanics of formation, preservation and distribution. Philosophical Transactions of the Royal Society B: Biological Sciences 352, 481-518.

Avanzini, M., Mietto, P., Panarello, A., De Angelis, M., Rolandi, G., 2008. The Devil's Trails: Middle Pleistocene human footprints preserved in a volcaniclastic deposit of Southern Italy. Ichnos 15, 179189.

Bates, K.T., Collins, D., Savage, R., McClymont, J., Webster, E., Pataky, T.C., D'Août, K., Sellers, W.I., Bennett, M.R., Crompton, R.C., 2013b. The evolution of compliance in the human lateral midfoot. Proceedings of the Royal Society of London B: Biological Sciences 280, 20131818. 
Bates, K.T., Savage, R., Pataky, T.C., Morse, S.A., Webster, E., Falkingham, P.L., Ren, L., Qian, Z., Collins, D., Bennett, M.R., McClymont, J., Crompton, R.H., 2013a. Does footprint depth correlate with foot motion and pressure? Journal of the Royal Society Interface 10, 20130009.

Behrensmeyer, A.K., 1975. The taphonomy and paleoecology of Plio-Pleistocene vertebrate assemblages east of Lake Rudolf, Kenya. Bulletin of the Museum of Comparative Zoology 146, 473578.

Behrensmeyer, A.K., Laporte, L.F., 1981. Footprints of a Pleistocene hominid in northern Kenya. Nature 289, 167-169.

Bennett, M.R., Morse, S.A., 2014. Human Footprints: Fossilised Locomotion? Springer, Dordrecht, The Netherlands.

Bennett, M.R., Morse, S.A., Falkingham, P.L., 2014. Tracks made by swimming Hippopotami: An example from Koobi Fora (Turkana Basin, Kenya). Palaeogeography, Palaeoclimatology, Palaeoecology 409, 9-23.

Bennett, M.R., Reynolds, S.C., Morse, S.A., Budka, M., 2016a. Laetoli's lost tracks: 3D generated mean shape and missing footprints. Scientific Reports 6, 21916.

Bennett, M.R., Falkingham, P., Morse, S.A., Bates, K.T., Crompton, R.H., 2013. Preserving the Impossible: Conservation of Soft-Sediment Hominin Footprint Sites and Strategies for ThreeDimensional Digital Data Capture. PloS One 8: e60755.

Bennett, M.R., Morse, S.A., Liutkus-Pierce, C., McClymont, J., Evans, M., Crompton, R.H., Thackeray, J.F., 2014b. Exceptional preservation of children's footprints from a Holocene footprint site in Namibia. Journal of African Earth Sciences 97, 331-341.

Bennett, M.R., Harris, J.W.K., Richmond, B.G., Braun, D.R., Mbua, E., Kiura, P., Olago, D., Kibunjia, M., Omuombo, C., Behrensmeyer, A.K., Huddart, D., Gonzalez, S., 2009. Early Hominin Foot Morphology Based on 1.5 Million Year Old Footprints from Ileret, Kenya. Science 323, 1197-1201.

Bramble, D.M., Lieberman, D.E., 2004. Endurance running and the evolution of Homo. Nature 432, 345-352.

Brown, F.H., Haileab, B., McDougall, I., 2006. Sequence of tuffs between the KBS Tuff and the Chari Tuff in the Turkana Basin, Kenya and Ethiopia. Journal of the Geological Society 163, 185-204.

Clarke, R.J. and Tobias, P.V., 1995. Sterkfontein Member 2 foot bones of the oldest South African hominid. Science 269, 521.

Crompton, R.H., Sellers, W.I., Thorpe, S.K.S., 2010. Arboreality, terrestriality and bipedalism Philosophical Transactions of the Royal Society of London B 365, 3301-3314.

Crompton, R.H., Pataky, T.C., Savage, R., D'Août, K., Bennett, M.R., Day, M.H., Bates, K., Morse, S., Sellers, W.I., 2011. Human-like external function of the foot, and fully upright gait, confirmed in the 3.66 million year old Laetoli hominin footprints by topographic statistics, experimental footprintformation and computer simulation. Journal of the Royal Society Interface 9, 707-719.

Day, M.H., Napier, J.R., 1964. Hominid Fossils from Bed I, Olduvai Gorge, Tanganyika: Fossil Foot Bones. Nature 201, 969-970.

Deino, A.L., 2011. 40Ar/39Ar dating of Laetoli, Tanzania. In: Harrison, T. (Ed.), Paleontology and geology of Laetoli: Human evolution in context. Springer, Netherlands, pp. 77-97. 
Dingwall, H.L., Hatala, K.G., Wunderlich, R.E., Richmond, B.G., 2013. Hominin stature, body mass, and walking speed estimates based on 1.5 million-year-old fossil footprints at Ileret, Kenya. Journal of 410 Human Evolution 64, 556-568.

411 Ditchfield, P., Harrison, T., 2011. Sedimentology, Lithostratigraphy and Depositional History of the Laetoli Area. In: Harrison, T., (Ed.), Paleontology and geology of Laetoli: Human evolution in context. Springer, Dordrecht, The Netherlands., pp. 47-76.

414 Drake, R., Curtis, G.H., 1987. Geochronology of the Laetoli fossil localities. In: Leakey, M.D., Harris, 415 J.M. (Eds.), Laetoli: A Pliocene Site in Northern Tanzania. Clarendon Press, Oxford, pp.48-52.

Feibel, C.S., Brown, F.H., McDougall, I., 1989. Stratigraphic context of fossil hominids from the Omo Group deposits: Northern Turkana Basin, Kenya and Ethiopia. American Journal of Physical Anthropology 78, 595-622.

Gebo, D.L., Schwartz, G.T., 2006. Foot bones from Omo: implications for hominid evolution. American Journal of Physical Anthropology 129, 499-511.

Granger, D.E., Gibbon, R.J., Kuman, K., Clarke, R.J., Bruxelles, L., Caffee, M.W., 2015. New cosmogenic burial ages for Sterkfontein Member 2 Australopithecus and Member 5 Oldowan. Nature 522, 85-88.

Harcourt-Smith, W.E., Aiello, L.C., 2004. Fossils, feet and the evolution of human bipedal locomotion. Journal of Anatomy 204, 403-416.

Harcourt-Smith, W.E.H., Throckmorton, Z., Congdon, K.A., Zipfel, B., Deane, A.S., Drapeau, M.S.M., Churchill, S.E., Berger, L.R., DeSilva, J.M., 2015. The foot of Homo naledi. Nature communications, 6.

Hatala, K.G., Wunderlich, R.E., Dingwall, H.L., Richmond, B.G., 2016a. Interpreting locomotor biomechanics from the morphology of human footprints. Journal of Human Evolution 90, 38-48.

Hatala, K.G., Roach, N.T., Ostrofsky, K.R., Wunderlich, R.E., Dingwall, H.L., Villmoare, B.A., Braun, D.R., Richmond, B.G. 2016b. Footprints reveal direct evidence of group behaviour and locomotion in Homo erectus. Scientific Reports, 6, 28766.

Hatala, K.G., Demes, B., Richmond, B.G., 2016c. Laetoli footprints reveal bipedal gait biomechanics different from those of modern humans and chimpanzees. Proceeding of the Royal Society B283, 20160235.

Hay, R.L., 1987. Geology of the Laetoli area. In: Leakey, M.D., Harris, J.M. (Eds.) Laetoli: A Pleistocene Site in Northern Tanzania. Clarendon Press, Oxford, pp. 23-47.

Isaac, G.L.I., Behrensmeyer, A.K., 1997. Geological context and palaeoenvironments. In: Isaac, G.L.I. (Ed.), Koobi Fora Research Project, Volume 5, Plio-Pleistocene Archaeology, Clarendon Press, 441 Oxford, pp. 12-70.

442 Kabsch, W., 1976. A solution for the best rotation to relate two sets of vectors. Acta Crystallographica 443 Section A 32, 922-923.

Kidd, R.S., O'Higgins, P.O, Oxnard, C.E., 1996. The OH8 foot: a reappraisal of the hindfoot utilizing a multivariate analysis. Journal of Human Evolution 31, 269-291.

446 Kim, K.S., Kim, J.Y., Kim, S.H., Lee, C.Z., Lim, J.D., 2009. Preliminary report on hominid and other 447 
Leakey, M.D., 1981. Tracks and tools. Philosophical Transactions of the Royal Society of London B, 449 Biological Sciences 292, 95-102.

450 Leakey, M.D., Harris, J.M., 1987. Laetoli: A Pliocene Site in Northern Tanzania. Clarendon Press, 451 Oxford, UK.

452 Leakey, M.D., Hay, R.L., 1979. Pliocene footprints in the Laetoli beds at Laetoli, Northern Tanzania. $453 \quad$ Nature 278, 317.

454 Lepre, C.J., Quinn, R.L., Joordens, J.C., Swisher, C.C., Feibel, C.S., 2007. Plio-Pleistocene facies 455 environments from the KBS Member, Koobi Fora Formation: implications for climate controls on the 456 development of lake-margin hominin habitats in the northeast Turkana Basin (northwest Kenya). 457 Journal of Human Evolution 53, 504-514.

458 Lockley, M., Roberts, G., Kim, J.Y., 2008. In the Footprints of Our Ancestors: An Overview of the 459 Hominid Track Record. Ichnos 15, 106-125.

460 Lovejoy, C.O., Latimer, B., Suwa, G., Asfaw, B., White, T.D., 2009. Combining prehension and propulsion: the foot of Ardipithecus ramidus. Science 326, 72-72e8.

Miall, A.D., 2016. Stratigraphy: A Modern Synthesis. Springer International Publishing.

Meldrum, D.J., Lockley, M.G., Lucas, S.G., Musiba, C., 2011. Ichnotaxonomy of the Laetoli trackways: the earliest hominin footprints. Journal of African Earth Sciences 60, 1-12.

Morse, S.A., Bennett, M.R., Liutkus-Pierce, C., Thackeray, F., McClymont, J., Savage, R., Crompton, R.H., 2013. Holocene footprints in Namibia: the influence of substrate on footprint variability. American Journal of Physical Anthropology 151, 265-279.

Moyà-Solà S., Köhler M., Alba D.M., 1999. Primate evolution - in and out of Africa. Current Biology 9 , 547-550.

Musiba, C.M., Mabula, A., Selvaggio, M., Magori, C.C., 2008. Pliocene animal trackways at Laetoli: Research and conservation potential. Ichnos 15, 166-178.

Pataky, T.C., Goulermas, J.Y., 2008. Pedobarographic statistical parametric mapping (pSPM): a pixel-level approach to foot pressure image analysis. Journal of Biomechanics 41, 2136-2143.

Raichlen, D.A., Gordon, A.D., Harcourt-Smith, W.E., Foster, A.D., Haas Jr, W.R., 2010. Laetoli footprints preserve earliest direct evidence of human-like bipedal biomechanics. PLoS One 5, p.e9769.

477 Roach, N.T., Hatala, K.G., Ostrofsky, K.R., Villmoare, B., Reeves, J.S., Du, A., Braun, D.R., Harris, 478 J.W., Behrensmeyer, A.K. and Richmond, B.G., 2016. Pleistocene footprints show intensive use of 479 lake margin habitats by Homo erectus groups. Scientific reports, 6.

480 Roberts, G., Gonzalez, S., Huddart, D., 1996. Inter-tidal Holocene footprints and their archaeological 481

Schmincke, H-U., Kutterolf, S., Perez, W., Rausch, J., Freundt, A., Strauch, W., 2009. Walking through volcanic mud: the 2,100 year old Acahualinca footprints (Nicaragua). Bulletin of Volcanology 71, 479-493.

Schmincke, H-U., Rausch, J., Kutterolf, S., Freundt, A., 2010. Walking through volcanic mud: the 
Scott, J.J., Renaut, R.W., Owen, R.B., 2008. Preservation and paleoenvironmental significance of a footprinted surface on the Sandai Plain, Lake Bogoria, Kenya Rift Valley. Ichnos 15, 208-231.

Scott, J.J., Renaut, R.W., Owen, R.B., 2010. Taphonomic controls on animal tracks at saline, alkaline Lake Bogoria, Kenya Rift Valley: impact of salt efflorescence and clay mineralogy. Journal of Sedimentary Research 80, 639-665.

Scrivner, P.J., Bottjer, D.J., 1986. Neogene avian and mammalian tracks from Death Valley National Monument, California: their context, classification and preservation. Palaeogeography, Palaeoclimatology, Palaeoecology 57, 285-331.

Suwa, G., 1984. Could Australopithecus afarensis have made the hominid tracks at Laetoli? Journal of Physical Anthropology 963, 224-225.

Szalay, F.S., Langdon, J. 1986. The foot of Oreopithecus bambolii: an evolutionary assessment. Journal of Human Evolution 15, 585-621.

Thorpe, S.K., Holder, R.L. and Crompton, R.H., 2007. Origin of human bipedalism as an adaptation for locomotion on flexible branches. Science 316, 1328-1331.

Thorpe, S.K.S., McClymont, J.M., Crompton, R.H., 2014a. The arboreal origins of human bipedalism. Antiquity 88, 906-914.

Thorpe, S.K.S., McClymont, J.M., Crompton, R.H., 2014b. Putting flesh on to hominin bones. Antiquity 88, 924-926.

Tuttle, R., Webb, D., Weidl, E., Baksh, M., 1990. Further progress on the Laetoli trails. Journal of Archaeological Science 17, 347-362.

Ward, C.V., Kimbel, W.H., Johanson, D.C., 2011. Complete fourth metatarsal and arches in the foot of Australopithecus afarensis. Science 331, 750-753.

White, T.D., Suwa, G., 1987. Hominid footprints at Laetoli: Facts and interpretations. American Journal of Physical Anthropology 72, 485-514.

Winder, I.C., King, G.C.P., Maud H. Devès, M.H., Bailey, G.N., 2013. Complex topography and human evolution: the missing link. Antiquity 87, 333-49.

Winder, I.C., King, G.C.P., Maud H. Devès, M.H., Bailey, G.N., 2014. Human bipedalism and the importance of terrestriality. Antiquity 88, 915-916.

Wood, B., 2014. Unreasonable expectations. Antiquity 88, 917-918.

Wolf, P., Stacoff, A., Stüssi, E., 2004. Modelling of the passive mobility in human tarsal gears implications from the literature. The Foot 14, 23-34.

Zipfel, B., DeSilva, J.M., Kidd, R.S., Carlson, K.J., Churchill, S.E., Berger, L.R., 2011. The foot and ankle of Australopithecus sediba. Science, 333, 1417-1420.

\section{Figure Captions}




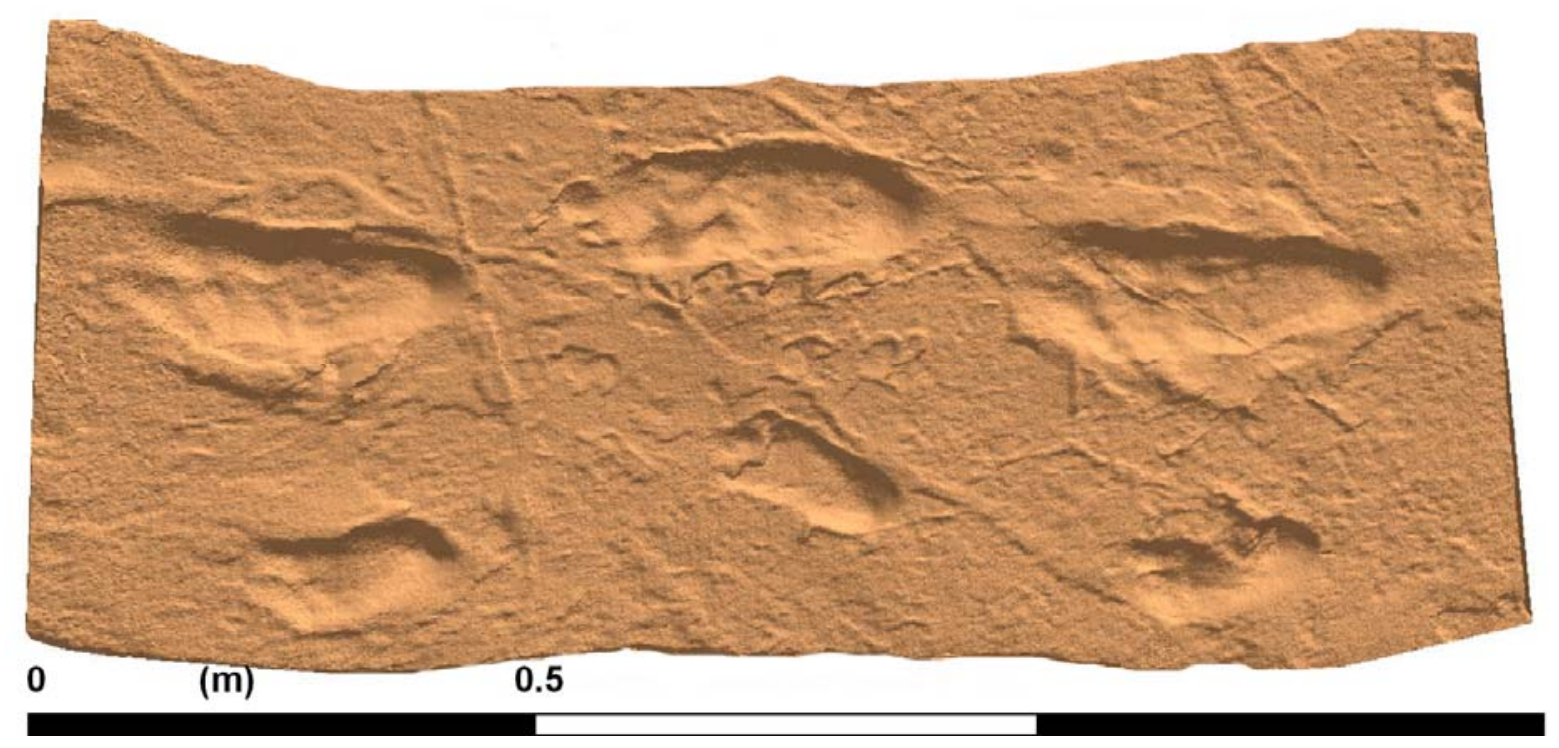

524 Figure 1: Optical laser colour rendered scan of part of the Laetoli trail. This was captured by the 525 senior author using a Vi900 Konica-Minolta scanner from a first generation cast held at the $526 \quad$ National Museum of Kenya in 2008. 



Figure 2: Mean tracks for the G1 and G3 trackways with superimposed contours at $1 \mathrm{~mm}$ vertical intervals. The data was captured by the senior author using a Vi900 Konica-Minolta scanner from a first generation cast held at the National Museum of Kenya in 2008 and processed in DigTrace and ArcGIS Version 10 (http://www.esri.com/software/arcgis). The G1 mean is based on eleven individual tracks: G1-23, G1-25, G1-26, G1-27, G1-31, G1-33, G1-34, G1-35, G1-36, G1-37, G139. The G3 mean is based on: G2-18, G2-26, G2-27, G2-28 and G2-29. 


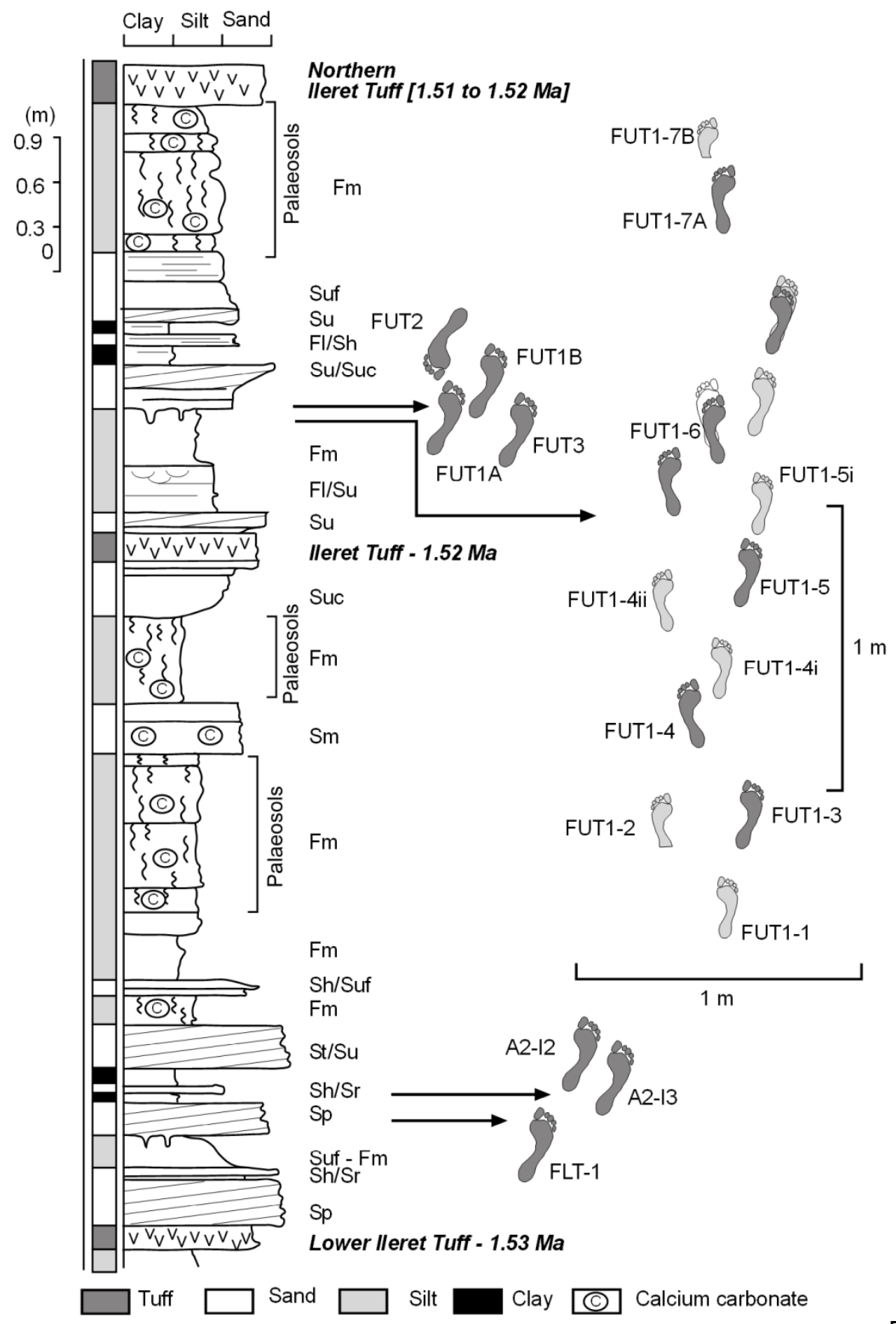

figures for the lleret tracks showing the stratigraphy and the excavated tracks as of 2011. Modified

535 figures for the lleret tracks showing the stratigraphy and the excavated tracks as of 2011. Modified
536 from Bennett et al. (2009) and Dingwall et al. (2013). The facies codes are after Maill (2016): Fm

$537=$ massive silt, $\mathrm{FI}=$ laminated silts, $\mathrm{Sm}=$ massive sands, $\mathrm{Sp}=$ planar cross-bedded sands, $\mathrm{Sh}=$

538 horizontally stratified sands; $\mathrm{Su}=$ scours and shallow cross-bedded sands, $\mathrm{Sr}=$ rippled sands, $\mathrm{St}=$ 539 trough cross-bedded sands, Suf = upward fining sands, Suc = upward coarsening sands. 

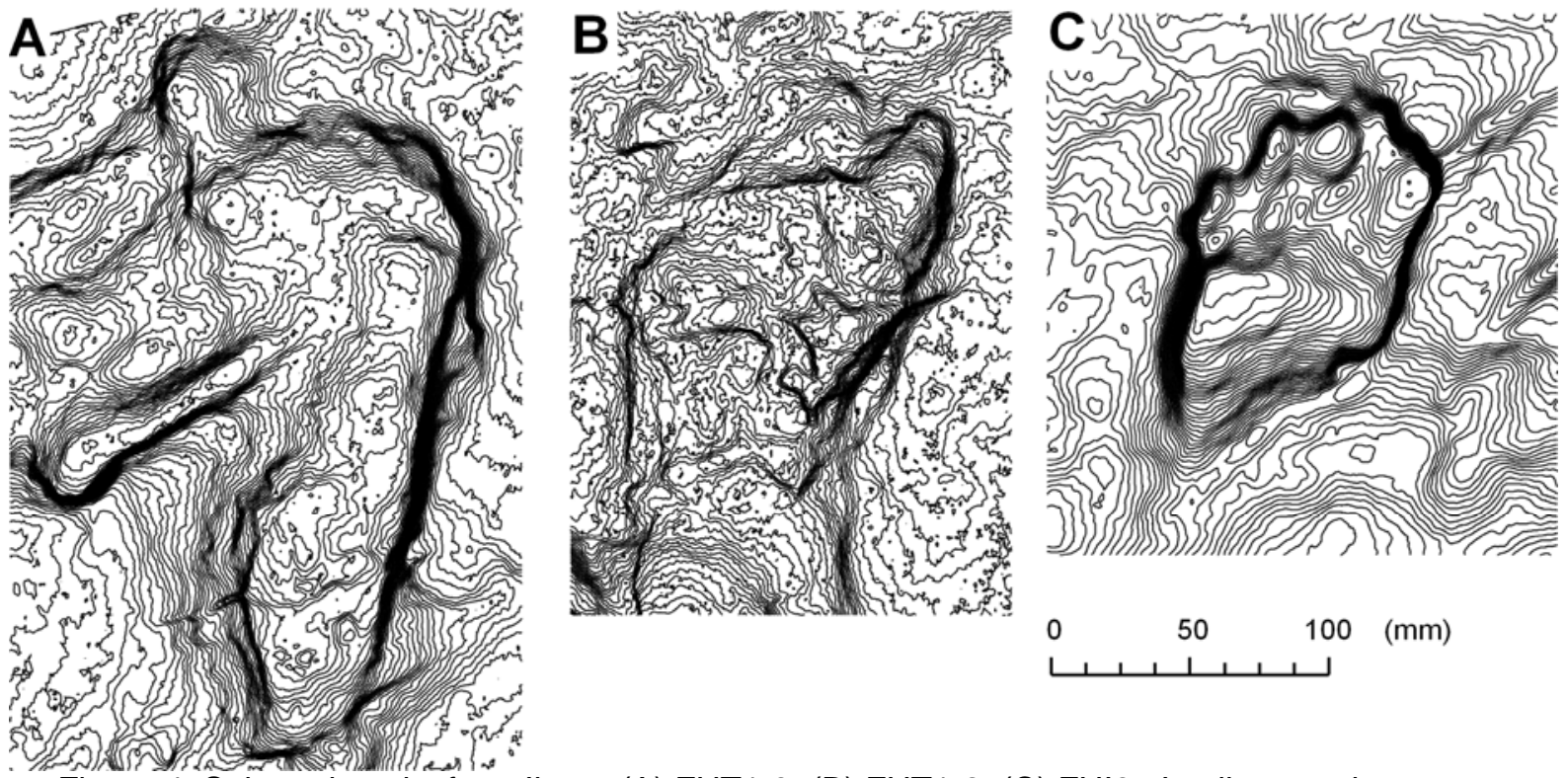

Figure 4: Selected tracks from Ileret: (A) FUT1-3, (B) FUT1-2, (C) FUI8. In all cases the contour interval is $1 \mathrm{~mm}$. The data was captured by the senior author in the field using a Vi900 KonicaMinolta scanner in 2007/2008 and processed in DigTrace and ArcGIS Version 10 (http://www.esri.com/software/arcgis). 
A

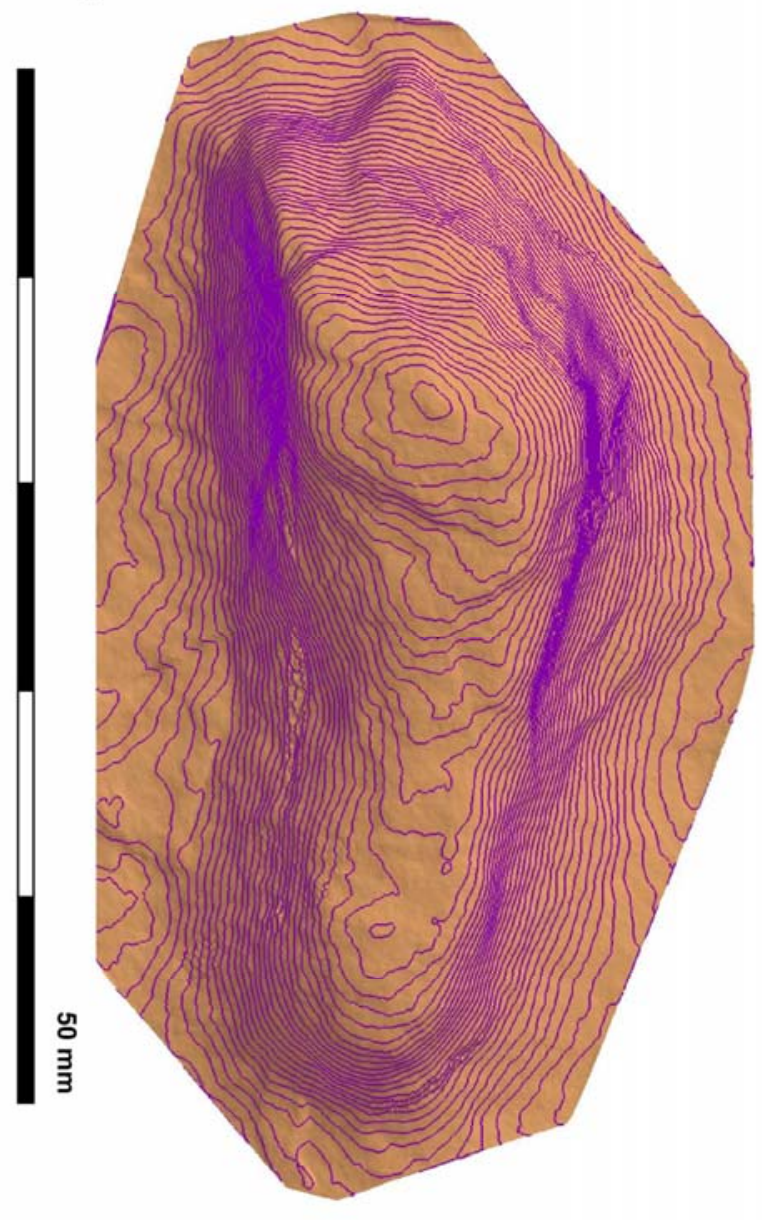

B

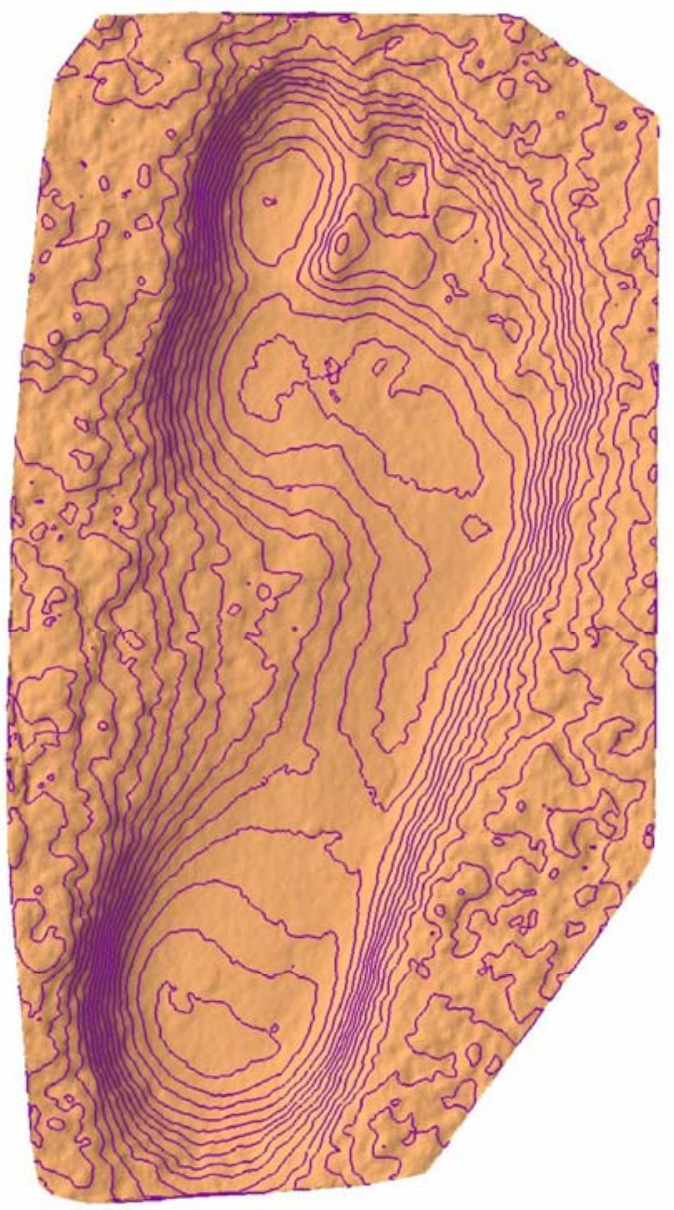

Figure 5: Mean tracks for the upper trail at Ileret (FwJj14E; A) and for the Daasanach modern mean $(B ; N=33)$ with superimposed contours at $1 \mathrm{~mm}$ intervals. The lleret mean is based on FUT1-1, FUT1-3, FUT1-5, FUT1-6 and FUT1-7A. This may include tracks from two individuals according to Dingwall et al. (2013). The data was captured by the senior author using a Vi900 Konica-Minolta scanner in the field in 2007/2008 and processed in DigTrace and ArcGIS Version 10 (http://www.esri.com/software/arcgis). 


\section{A. Size + shape}

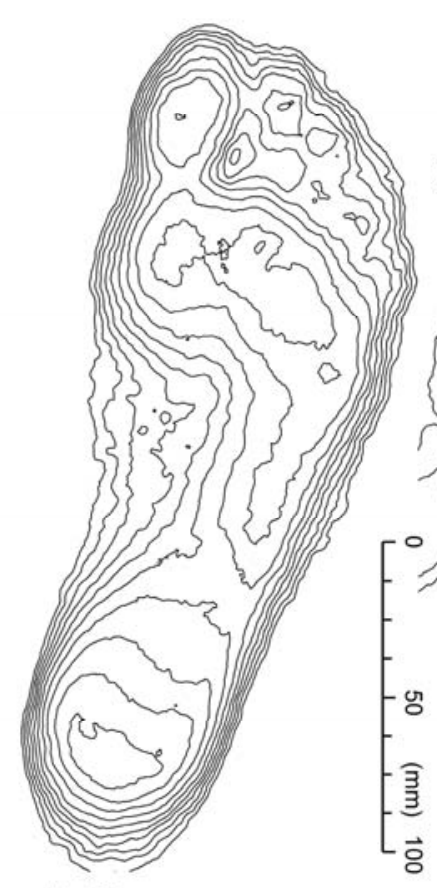

B. Shape

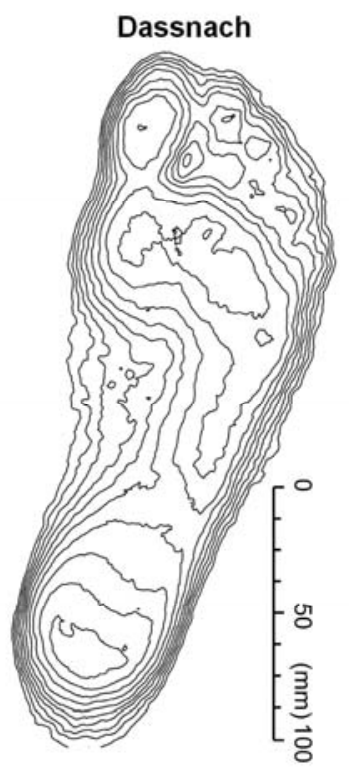

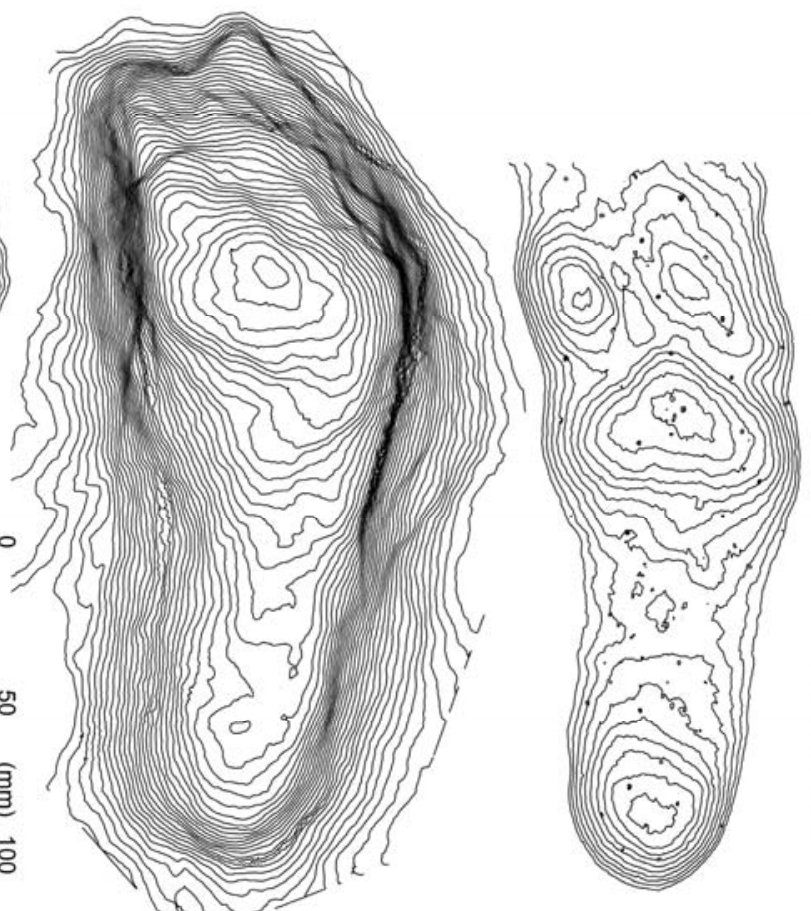

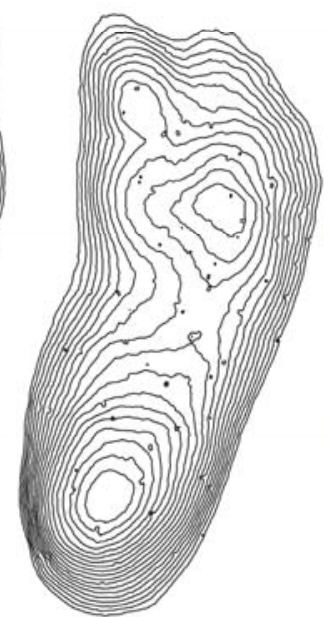

G1 Mean
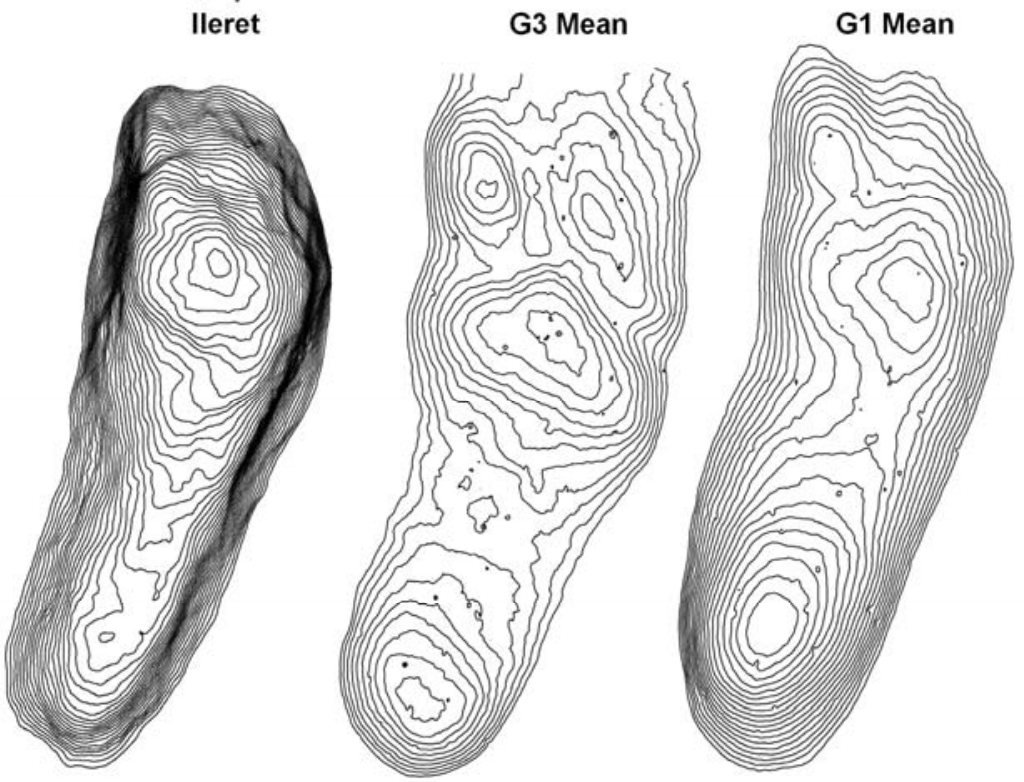

Figure 6: Mean track for the various track populations available across the Australopith to Homo transition. A. Tracks reproduced at relative size. B. Tracks registered against the Daasanach mean in DigTrace using an affine transformation thereby removing the influence of size. 


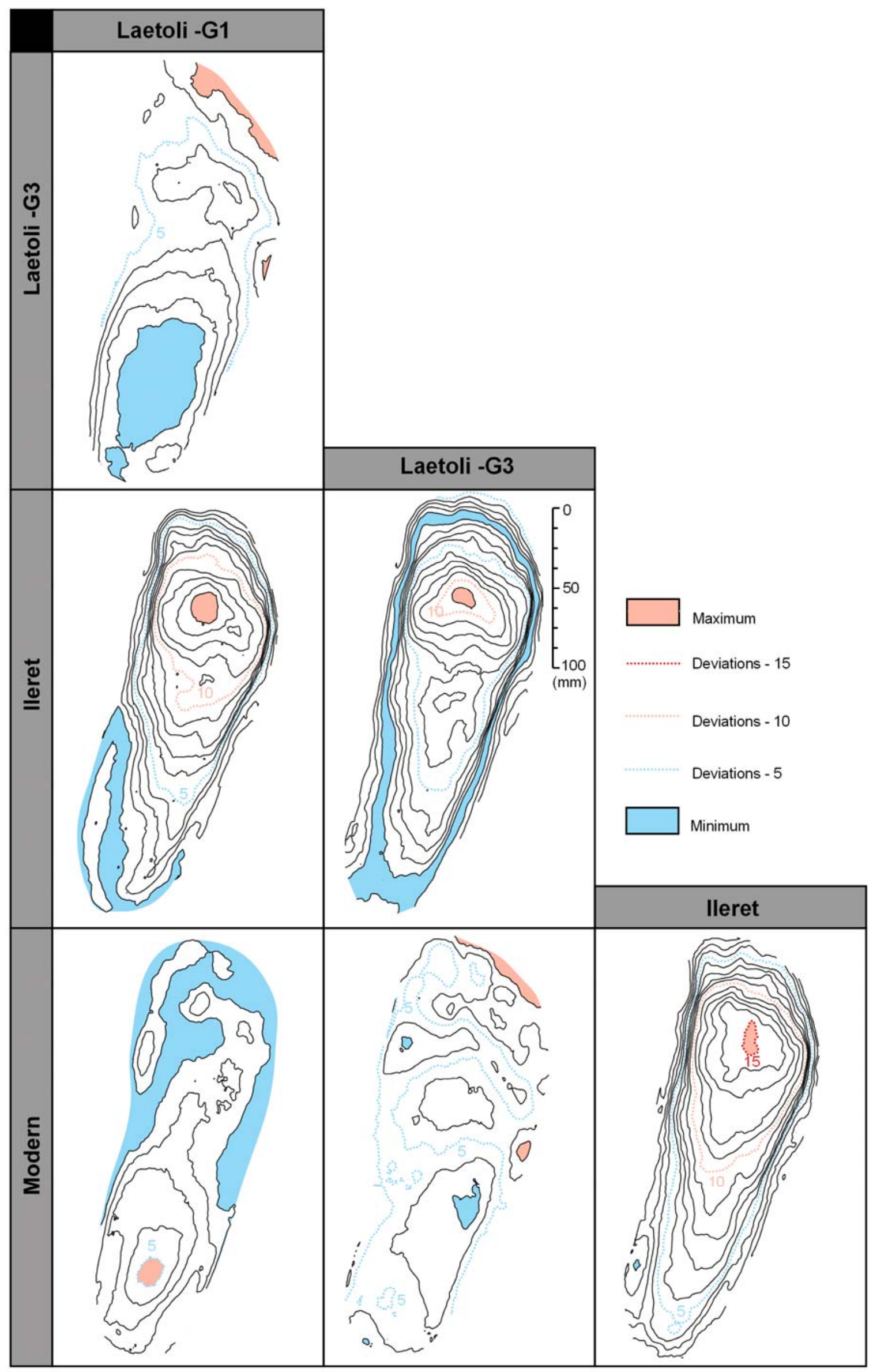



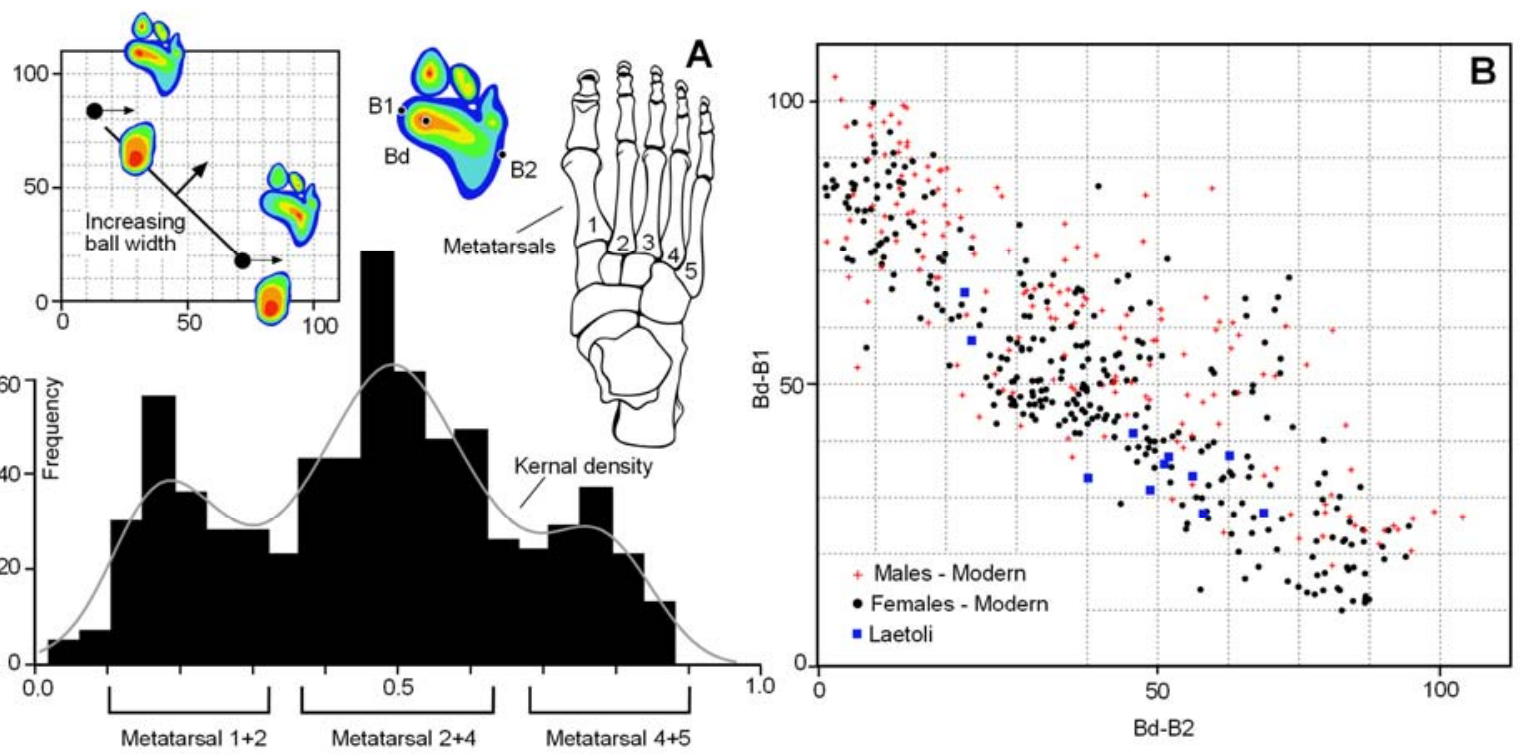

Figure 8: Simple landmark based experiment to explore the degree of medial transfer. A. modern tracks (habitually shod) plus data from the G1 Laetoli trackway. 